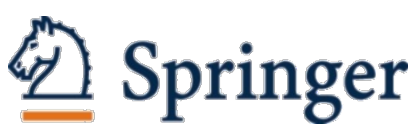

\section{Kinematics of Breaking Waves}

De Wang Chia*, Yali Zhang,

Lloyd's Register Singapore Pte Ltd, Singapore

\section{Arun Kr Dev, Xin Wang}

Marine Technology

Newcastle University in Singapore, Singapore

Longbin Tao

Naval Architecture, Ocean and Marine Engineering

University of Strathclyde, Glasgow G4 0LZ, United Kingdom

* Corresponding author, De Wang Chia, d.w.chia@ncl.ac.uk 


\begin{abstract}
One important kinematic properties of breaking waves is the wave celerity. Constant wave celerity has been used for the wave breaking criterion by many researchers. However, this approach does not consider the variation of wave celerity at different phases before breaking. Hence, this paper examines the aspects of the wave breaking criterion and dynamics of wave celerity before wave breaking. Breaking waves were generated using the JONSWAP focused spectrum and a semi-empirical formula for the wave celerity estimation was established.
\end{abstract}

KEY WORDS: Plunging wave, wave breaking, wave celerity, wave tank, wave kinematics

\title{
INTRODUCTION
}

Wave breaking induces an additional significant slamming load on offshore structures and understanding the kinematics behind this extreme event would be beneficial in many aspects, in areas of offshore structure design, and the physical science of water waves.

Predicting the occurrence of a breaker has generated great interest amongst researchers. One of the commonly used kinematic criteria is the 'U/c' ratio; ' $U$ ' being the horizontal crest particle velocity, and ' $c$ ' being the phase speed. It is accepted that if the horizontal crest velocity exceeds the wave celerity, the crest will form a jet and would subsequently topple due to gravitational forces. However, recent literature and observations from several researchers have shown contradictory results from this theory.

Kjeldsen [1] created breaking waves via the superposition of 43 regular waves of carrying frequencies. High speed cameras were used for the capturing of the horizontal crest particle velocity. The phase speed was calculated using wave probes, via the zero-upcrossing method. He measured a 'U/c' ratio of 1.73 upon breaking.

$$
c=g * \frac{T_{Z}}{2 \pi}
$$

$\mathrm{g}=$ gravitational acceleration, $9.81 \mathrm{~ms}^{-2}$

$\mathrm{T}_{\mathrm{Z}}=$ zero-downcrossing period, the time (seconds) taken for a successive wavelength, measured at the free surface.

Perlin [2] created breaking waves via dispersive focusing, which involved a range of wave frequencies to generate breaking waves. PIV (Particle Image Velocimetry) and PTV (Particle Tracking Velocimetry) were used to determine the fluid's particle velocity. He went on and generated the plunging breaker and found that the wave length prior to breaking is $0.7 \mathrm{~m}$, which gave a phase speed of $1.05 \mathrm{~m} / \mathrm{s}$; according to linear wave theory. The measured phase speed of $1.08 \mathrm{~m} / \mathrm{s}$ matched a close approximation of the calculated value.

Perlin [2] found that the PIV-measured ' $U$ ' was $0.8 \mathrm{~m} / \mathrm{s}$, which was approximately $25 \%$ lower than the measured phase velocity. However, the PTV-measured ' $U$ ' was showing signs of the horizontal crest particle velocity surpassing the phase speed. Perlin [2] concluded that prior to breaking, the crest front becomes nearly vertical and the wave particle at the crest starts to accelerate horizontally. 
Stansell and Macfarlane [3] performed experiments using a focused spectrum to generate plunging breakers and spilling breakers to observe the 'U/c' ratio upon breaking. Wave gauges were used for surface elevation measurements and PIV for the measurement of the surface crest particle velocity. It is found that the 'U/c' recorded for plunging and spilling breakers were 0.81 and 0.95 respectively; which was less than 1 . It is further confirmed that the common understanding of ' $U / c$ ' ratio > 1, was not a necessary criterion to predict the onset of a breaker.

However, the phase speed of a wave, just before undergoing breaking, would experience dramatic kinematic changes. It might not be accurate to assume a constant phase speed for the entire phase of the pre-breaking wave. Understanding the kinematics of wave breaking, would be beneficial for understanding the geometry breaking criterion and breaking wave impact loading.

Not limiting to kinematic breaking criterion, geometric breaking criterion were one of the most debated topics in recent decades. Traditionally, wave steepness ( $a k$ ) had been used to describe wave breaking parameter; $k=$ wave number, $a$ = wave amplitude. However, in the actual case, non-linear waves behaved in an asymmetrical manner. The crest of a near breaking wave would be more than $0.5 H$ ( $H$ = wave height), and the crest front length of the wave wouldn't be exactly $0.25 L$ ( $L$ = wavelength).

Kjeldsen and Myrhaug [4] separate wave steepness into two geometric parameters. They introduced ' $\varepsilon$ ' \& ' $\delta$ ' which were used to describe crest-front and crest-rear steepness respectively. These new geometric breaking parameters took into consideration the asymmetric behaviour of non-linear waves.

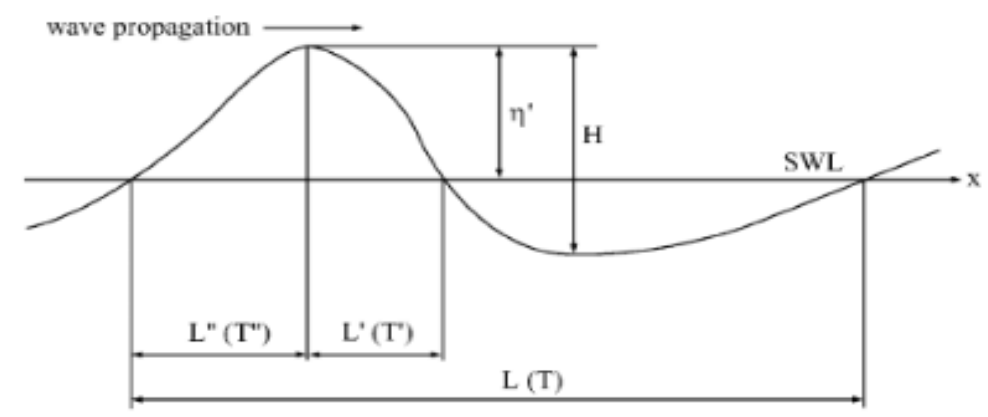

Fig. 1 Local wave parameters defined by Kjeldsen and Myhuang [4]

The crest-front steepness can be written as,

$$
\varepsilon=\frac{\eta^{\prime}}{L^{\prime}}=\frac{\eta^{\prime}}{\frac{g}{2 \pi} * T_{Z} * T^{\prime}}
$$

The crest-rear steepness can be written as,

$$
\delta=\frac{\eta^{\prime}}{L^{\prime \prime}}=\frac{\eta^{\prime}}{\frac{g}{2 \pi} * T_{Z} * T^{\prime \prime}}
$$

However, for simplicity, researchers using wave probes in their experimental studies had been applying the above equation to calculate both the crest-front and crest-rear steepness. In the above equations, it was noted that a 
constant phase speed was used for deriving the crest-front and crest-rear length respectively. Breaking wave is a dynamic phenomenon, hence assuming a constant phase speed during the entire phase of the wave might cast a shadow on the accuracy of the applied formulas used above.

Chan. et al [5] suggested that breaking wave is shown to be the most destructive, when there is a well-formed jet due to the association of the additional slamming load induced by the jet. Alagan et al [6], further proposed expanding the Morison's Equation to account for the additional wave breaking force arising from the breaking wave by including an additional slamming force term into the existing drag and inertia term.

The equation is as follows:

$$
F_{S}=0.5 * \rho * C_{S} * C_{B}^{2} * \lambda * \eta
$$

$\boldsymbol{\rho}=$ density of medium $\left(\mathrm{kg} / \mathrm{m}^{3}\right)$

$\mathrm{C}_{\mathrm{S}}=$ Slamming force coefficient

$\mathrm{C}_{\mathrm{B}}=$ Breaking wave celerity $\left(\mathrm{ms}^{-1}\right)$

$\lambda=$ Curling factor of breaking wave, express as a ratio of the impact length on cylinder over the breaking wave elevation

$\eta=$ Surface elevation (m)

$\lambda * \eta=$ Breaking wave impact area on structure per unit length $\left(\mathrm{m}^{2} / \mathrm{m}\right)$

Synthesising and interpreting the dynamics leading up to wave breaking is essential to research in this area. In this present study, experimental work would be carried out to generate breaking waves of different intensities.

The aim of this research is to establish the dynamic behavior of the breaking wave kinematics at the point of jet forming and to revisit past literature surveys of the kinematic breaking criterion.

\section{EXPERIMENTS}

Breaking waves were generated at Newcastle University, in the Wind, Wave and Current tank measuring 11m by $1.8 \mathrm{~m}$ by $2 \mathrm{~m}$, length, width and height respectively, via the focused spectrum method. This wave tank uses a piston type wave maker, and with the input of the relevant wave parameters, the wave maker's strokes displacements were calculated by the computer software.

The creation of breaking waves used the JONSWAP spectrum. The breaking wave intensities were modified by adjusting the peak frequency value. The breaking wave could be intensified by lowering the peak frequency value due to the negative correlation between the peak frequency and the spectrum.

The JONSWAP spectrum as follows:

$$
\begin{aligned}
& S_{J}(\omega)=\frac{\alpha * g^{2}}{\omega^{5}} * \exp \left[-1.25 *\left(\frac{\omega_{P}}{\omega}\right)^{4}\right]^{*} \gamma^{r} \\
& \omega=\text { angular frequency }(\mathrm{rad} / \mathrm{s}) \\
& \omega_{\mathrm{p}}=\text { peak angular frequency }(\mathrm{rad} / \mathrm{s}) \\
& \gamma^{\mathrm{r}}=\text { peak enhancement factor }
\end{aligned}
$$


The JONSWAP spectrum describes the irregular sea state with dozens of regular waves with varying frequencies; in this case a frequency range of $0.25 \mathrm{~Hz}$ to $2 \mathrm{~Hz}$.

And the surface elevation can be expressed by

$$
\eta=\sum_{n=1,2,3 \ldots} a_{n} \cos \left(k_{n} x-\omega_{n} t+\phi_{n}\right)
$$

$a=$ amplitude (m)

$k$ = wave number $(\mathrm{rad} / \mathrm{m})$

$\emptyset=$ phase shift (rad)

$\mathrm{x}$, being the spatial distance $(\mathrm{m})$ from the wave maker

A breaking focal point $\left(x_{B}\right)$ was chosen; in this case $9 \mathrm{~m}$. To unleash the full potential of the wave package and to obtain the critical amplitude to aid the generation of a breaker, each of the individual wave phase would be modified to satisfy the below equation

$$
\begin{aligned}
& \cos \left(k_{n} x-\omega_{n} t+\phi_{n}\right)=1 \\
& \left(k_{n} x-\omega_{n} t+\phi_{n}\right)=2 \pi * m \quad(\mathrm{~m}=0,1,2,3 \ldots)
\end{aligned}
$$

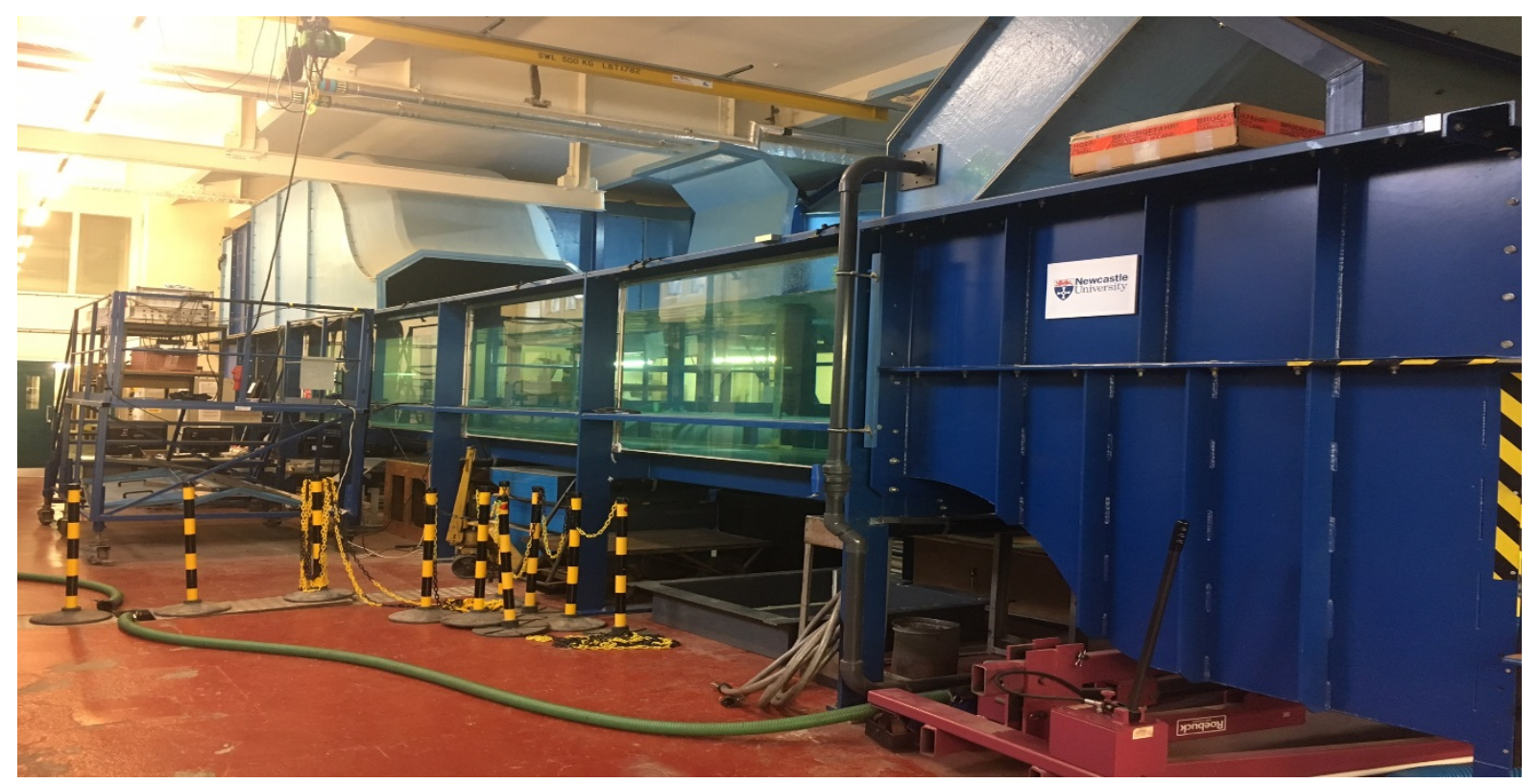

Fig. 2 Newcastle University Wind Wave and Current Tank

Wave probes having recording frequency of $100 \mathrm{~Hz}$, were placed at $\mathrm{x}=7.25 \mathrm{~m}, 7.75 \mathrm{~m}, 8 \mathrm{~m}, 8.5 \mathrm{~m}$, and $9 \mathrm{~m}$ respectively. Camera having a recording capability of 240fps was placed just before the breaking location.

\section{Post Process}

Breaking waves of 6 different intensities were generated in this study, having a peak frequency ranging from 0.47 to $0.52 \mathrm{~Hz}$, referring back to equation (Eq. 5); a lower peak frequencies would equate to stronger breaking intensities. 


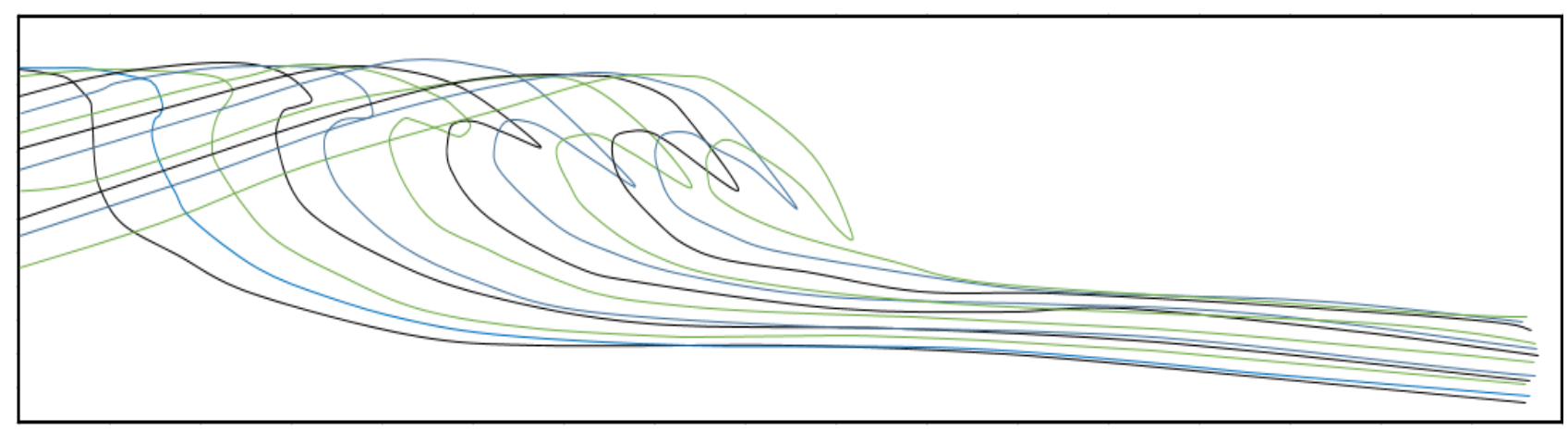

Fig. 3 Wave profile time history of $F_{p}=0.49 \mathrm{~Hz}$, focused JONSWAP spectrum, time step $=0.023 \mathrm{~s}$. The image shows a time history of the initial formation of the jet till the overturning of the jet.

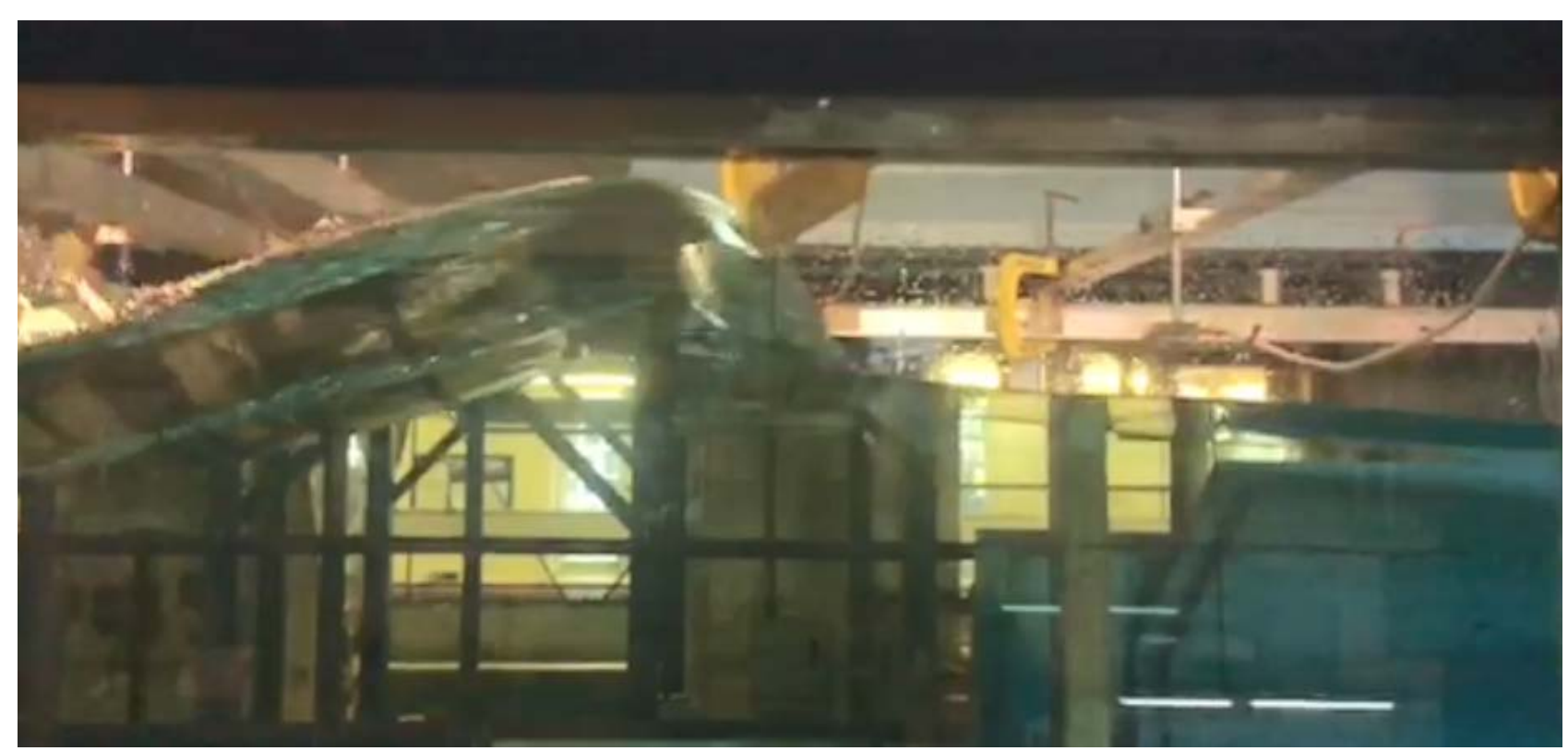

Fig. 4 Jet overtopping

The value of the horizontal crest particle velocity and wave celerity was measured by wave probes and high speed cameras respectively. Using both wave probe (Eulerian method) and high speed camera (Lagrangian method) of 240fps, horizontal crest particle velocity and wave celerity just before breaking were measured and compared.

Wave celerity measured by the zero crossing method via the probes, known as the Eulerian Wave Celerity. The horizontal crest velocities were estimated by the time needed for the crest to travel to the succeeding probes.

$$
\begin{aligned}
& C_{E}=\frac{g * T_{Z}}{2 \pi} \\
& U_{E}=\frac{x_{N+1}-x_{N}}{t_{\text {Crest }, N+1}-t_{\text {Crest }, N}}
\end{aligned}
$$

$\mathrm{x}_{\mathrm{N}}=$ spatial distance of a wave probe (m) 
$\mathrm{X}_{\mathrm{N}+1}=$ spatial distance of a succeeding wave probe $(\mathrm{m})$

$\mathrm{t}_{\text {Crest }, \mathrm{N}}=$ time $(\mathrm{s})$, when crest reaches probe $\mathrm{N}$,

$\mathrm{t}_{\text {Crest }, \mathrm{N}+1}=$ time $(\mathrm{s})$, when crest reaches successive probe,

However, the above Eulerian method didn't account for the dynamic changes of the kinematics of breaking wave; just before breaking. This Eulerian method assumed constant wave celerity during the entire breaking wave period, which contributed a level of inaccuracy. The use of the maximum crest values for wave probes with different spatial, wouldn’t necessary accurately describe the actual horizontal crest velocity, as the jet does not occur at the maximum crest value during collapsing. Hence, high speed camera of $240 \mathrm{fps}$ was used to determine the wave celerity and the jet velocity, simply using $\mathrm{dx} / \mathrm{dt}$.

The obtained wave celerity via the Lagrangian method, during the rise of the crest before breaking hereby known as ' $c_{1}$ '

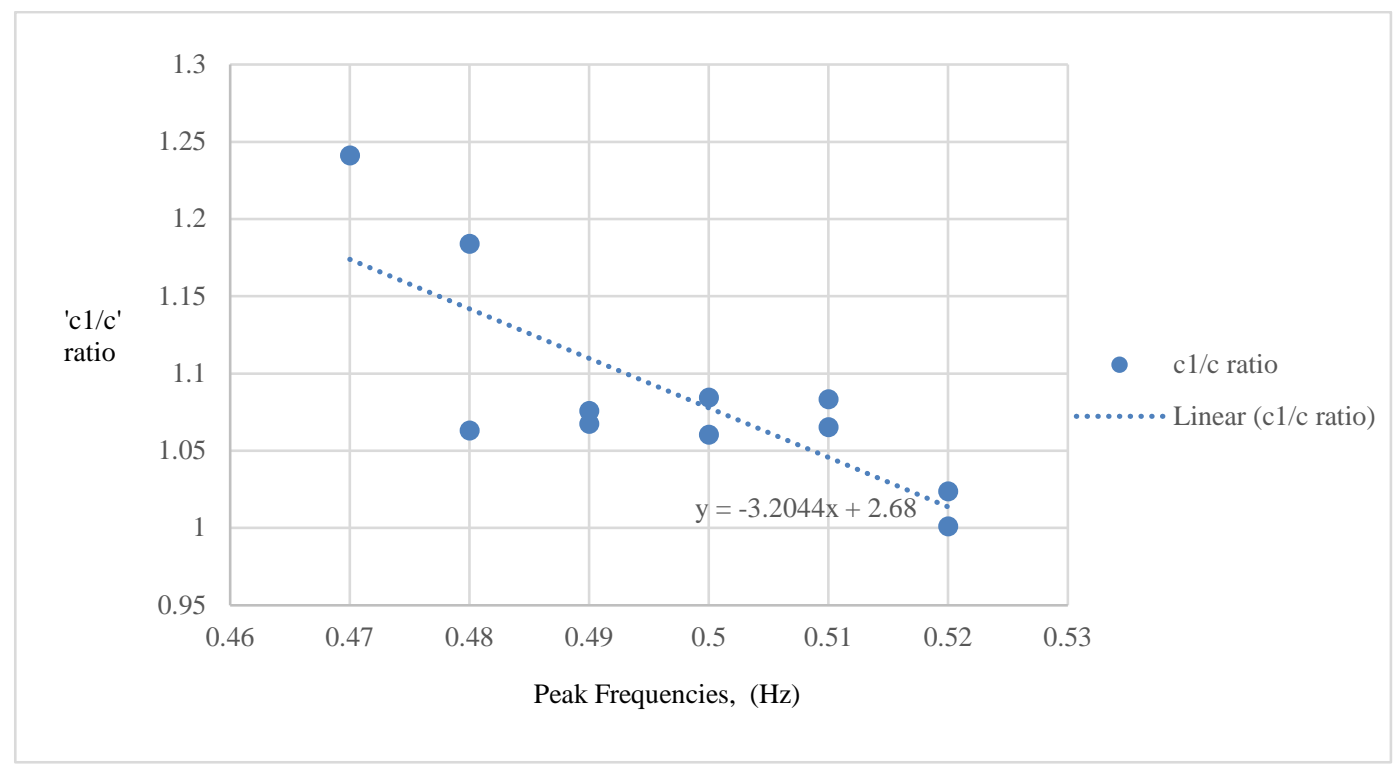

Fig. 5 ‘c1/CE’ ratios for different breaking intensities

The ' $c 1 / C_{E}$ ' ratios range from a value of 1 to 1.24 and it also appears that the actual wave celerity ' $c 1$ ' is slightly higher than ' $c_{E}$ ' just before breaking at $\mathrm{x}=8 \mathrm{~m}$. It is worthwhile to note that a higher ' $c 1 / c_{E}$ ' ratio was obtained with increasing breaking wave intensity as compared to decreasing wave celerity readings.

The obtained horizontal crest velocity via the Lagrangian method, is hereby known as ' $U 1$ ' 


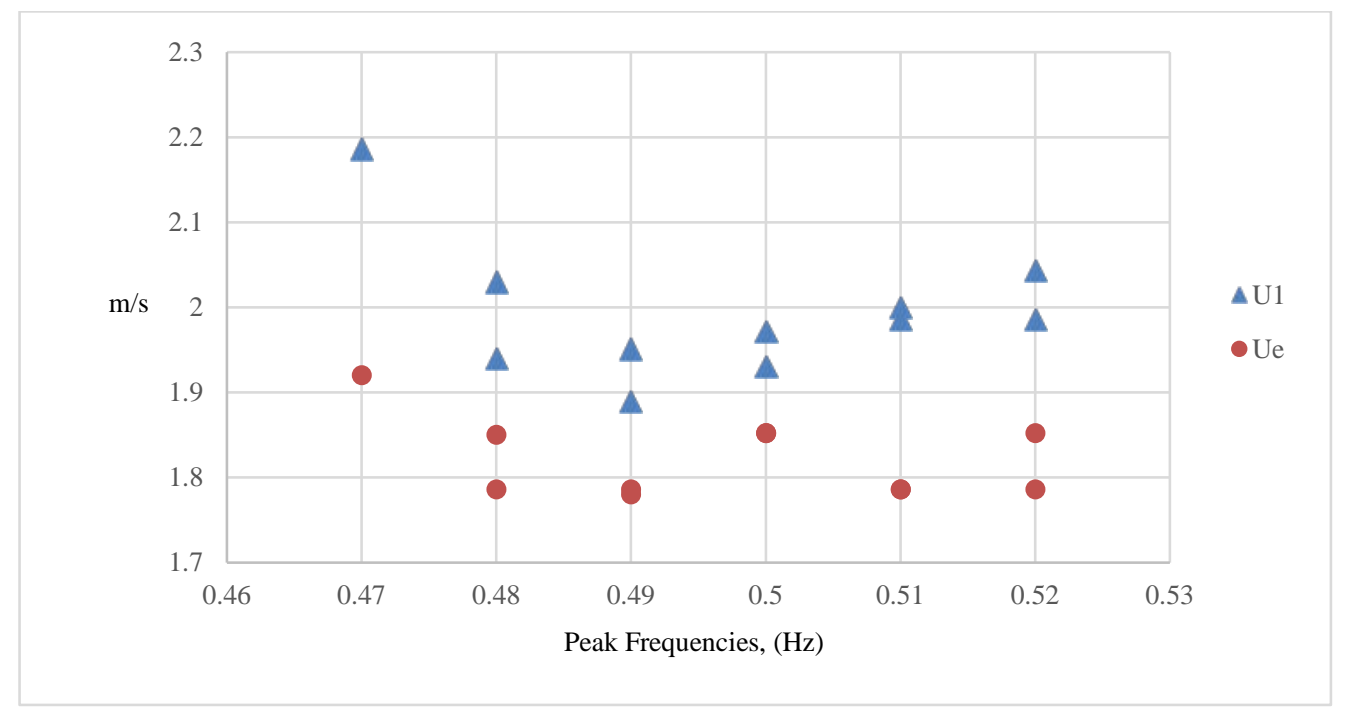

Fig. 6 ' $U 1 \& U_{E}$ ' values for different breaking intensities at $\mathrm{x}=8 \mathrm{~m}$

The horizontal crest velocity obtained via the Lagrangian method is greater than the linear eulerian method. The values of both ' $U 1$ ' \& ' $U e$ ' increases with greater breaking intensities (for $\mathrm{Fp}<0.49$ ).

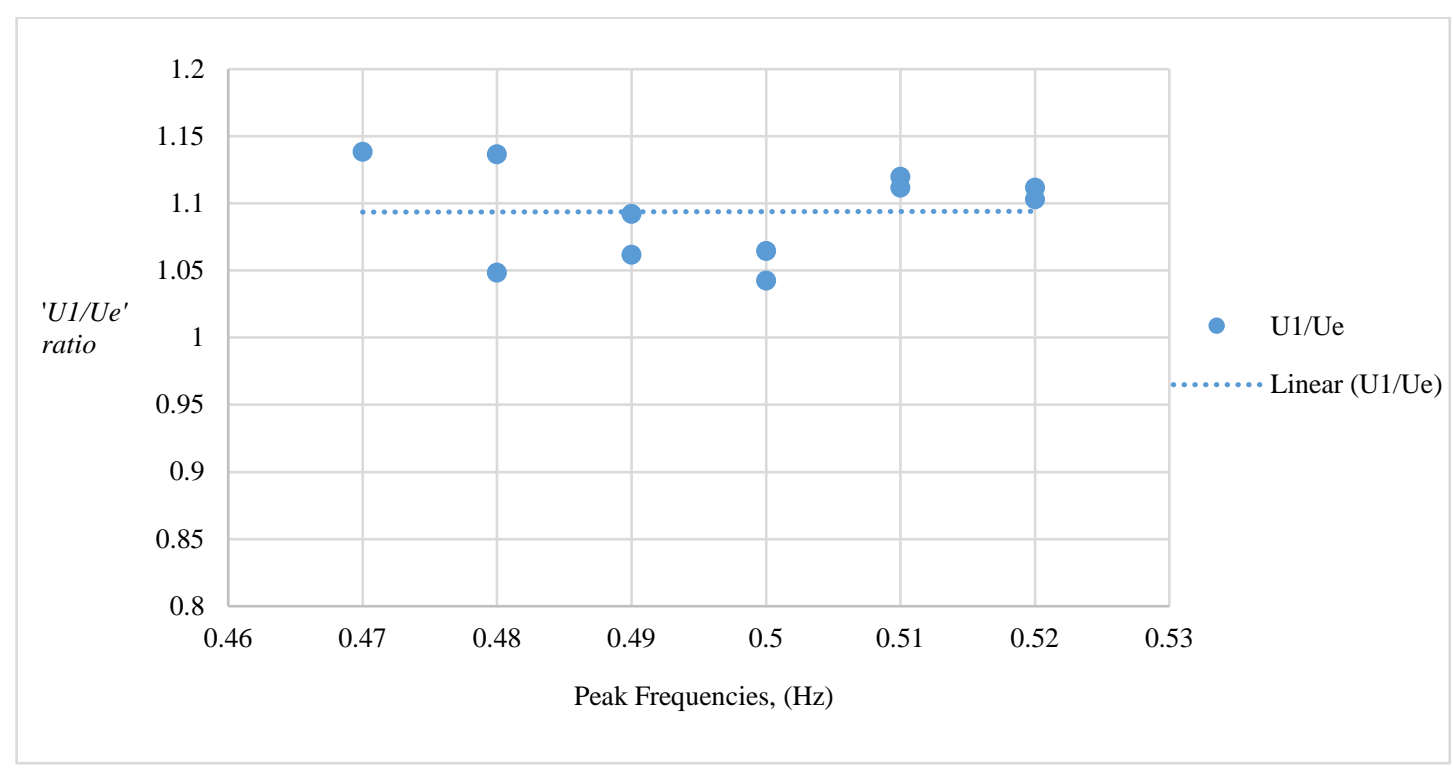

Fig. 7 ' $U 1 / U E$ ' values for different breaking intensities at $\mathrm{x}=8 \mathrm{~m}$

Contrary to the findings of the ' $c 1 / c_{E}$ ' ratio, the ' $U 1 / U e$ ' ratio is not affected by the breaking wave intensities. The 'U1/Ue' ratio ranges from 1.04 to 1.14 .

\section{Kinematic Analysis}

The maximum ' $U / c$ ' tends to occur at $\mathrm{x}=8 \mathrm{~m}$, just before the formation of the plunging jet. According to above findings, before wave breaking, the wave celerity remains constant and the horizontal crest velocity increases with the increasing wave breaking intensities, give a higher ' $U / C$ ' ratio. According to the above findings, the value of ' $U$ ' tends to be different depending on the methodology used. In this study, ' $U 1$ ' tends to be 8 to $14 \%$ greater than the 
horizontal crest velocity measured by the wave probes, and the differential increases with stronger wave breaking intensities. The value of ' $c 1$ ' also tends to be 7 to $24 \%$ greater than the Eulerian wave celerity. As a result, an overall a lower value of ' $U 1 / c 1$ ' ranging from 1.26 to 1.31 was achieved, as compared to 1.27 to 1.48 using the reading post-process from wave probes. Both methodologies achieved ' $U / c$ ' ratio $>1$, satisfying the kinematics breaking criteria, with the ' $U 1 / c 1$ ' giving a lower maximum value of 1.31 for the strongest breaker in this study.

The wave celerity based on the $3^{\text {rd }}$ order Strokes theory can be written as

$$
c=\frac{g^{*} T_{Z}}{2 \pi} *\left(\left(1+0.5(a k)^{2}\right)+\mathrm{O}(a k)^{4}\right)
$$

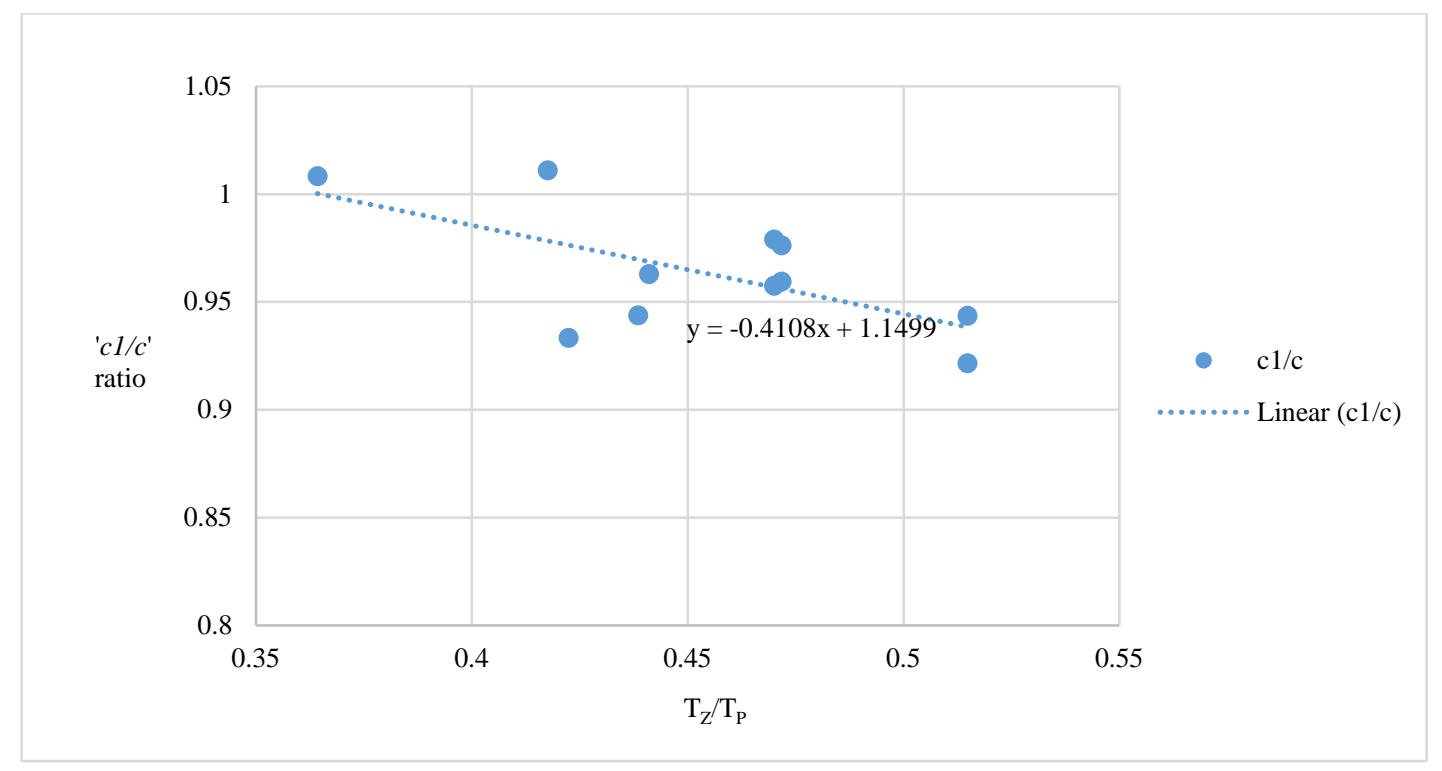

Fig. 8 ' $c 1 / c$ ' values for different non-dimensional breaking intensities ' $\mathrm{T}_{\mathrm{Z}} / \mathrm{T}_{\mathrm{P}}$ ' at $\mathrm{x}=8 \mathrm{~m}$, using $3^{\text {rd }}$ order Stokes theory

Comparing the ' $c 1 / c$ ' ratio against ' $\mathrm{T}_{\mathrm{z}} / \mathrm{T}_{\mathrm{P}}$ ' ratio; in which a lower ' $\mathrm{T}_{\mathrm{Z}} / \mathrm{T}_{\mathrm{P}}$ ' represents higher breaking intensities (Eq. 5), a regression analysis of the parameters is shown above.

Hence the semi-empirical breaking wave celerity is formulated as below,

$$
c 1=\frac{g * T_{Z}}{2 \pi} *\left(\left(1+0.5(a k)^{2}\right) *\left(1.1499-0.4108 *\left(\frac{T_{Z}}{T_{P}}\right)\right)\right.
$$

\section{DISCUSSION}

It is convenient to use the Eulerian method to measure wave celerity. However, for strong nonlinear waves, this method proved to be questionable.

Breaking waves with varying breaking intensities were generated, and a semi-empirical relation of the breaking wave celerity was established as above.

There is a negative correlation amongst ' $c 1$ ' and ' $\mathrm{T}_{\mathrm{Z}} / \mathrm{T}_{\mathrm{P}}$ ' ratio, meaning that the predicted breaking wave speed 
increases with increasing wave breaking intensities (lower $\mathrm{T}_{\mathrm{Z}} / \mathrm{T}_{\mathrm{P}}$ ratio).

The above equation would not hold, for non-breaking waves or waves with higher ' $\mathrm{T}_{\mathrm{Z}} / \mathrm{T}_{\mathrm{P}}$ ' ratios.

\section{CONCLUSIONS}

This study has explored the dynamic nature of wave leading to breaking. It was found that leading up to wave breaking, the wave celerity decreases and allowing the horizontal crest velocity to exceed, forming a jet which finally leads to breaking. Past literature survey [1][4], assuming a constant wave celerity, would have underestimated the crest-front length and overestimated the geometry breaking criteria by a significant margin depending on the breaking intensities, and also overestimating the kinematic breaking criteria.

In past literature survey [6], the slamming load formula acting on a cylinder is largely dependent on the breaking wave celerity (Eq. 4)

Researchers have been proposing wave models [7], [8], [9] to predict the value of the slamming load coefficient. Using the above semi-empirical formula to predict the breaking wave celerity, it would benefit future work on analysing the additional slamming load that acts on a structure due to wave breaking. A more accurate slamming coefficient based on the above theory could be modelled. The above semi-empirical formula would give a convenient method for estimation of kinematics of breaking waves just by using wave probes.

\section{ACKNOWLEDGEMENTS}

The authors would like to express their gratitude towards Singapore Economic Development Board (EDB) and Lloyd's Register Singapore Pte Ltd for funding this project work. Special thanks to the Hydrodynamics Lab Team at Newcastle University who provided assistance throughout the experimental works.

\section{REFERENCES}

1. S.P. Kjeldsen, (1984). The experimental verification of numerical models of plunging breakers. $19^{\text {th }}$ International Conference on Coastal Engineering

2. Perlin. M, He. J.H, Bernal. L.P, (1996). An experimental study of deep water plunging breakers. Physics of fluids, Vol 8, Issue 9, 2365-2374

3. Stansell Paul, and Macfarlane Colin, (2002). Experimental investigation of wave breaking criteria based on wave phase speeds. Journal of Physical Oceanography, May2002 Vol, 1269-1283

4. S.P. Kjeldsen and Myrhaug, (1979). Breaking waves in deep water and resulting wave forces. Offshore Technology Conference

5. Chan E.S, Cheong H.F, Gin K.Y.H, (1995). Breaking-wave loads on vertical walls suspended above mean sea level. Journal of Waterway, Port, Coastal and Ocean Engineering, Vol 121, No. 4

6. Alagan Chella, M. Alf Torum, Dag Myrhaug (2012). An overview of wave impact forces on offshore wind turbine substructures. Energy Procedia, Vol 20, 2012, 217-226

7. Cui Cheng, Zhang Ning-Chuan, Zuo Shu-Hua, Fang Zhuo (2013). A study on Kinematics Characteristic of Freak Wave. China Ocean Eng., Vol. 27, No. 3, pp. 391-402

8. Det Norske Veritas (DNV), (2010a). OS-J101 Design of Offshore Wind Turbine Structures.

9. Sarpkaya, T., (1978). Wave Impact Loads on Cylinders. Offshore Technology Conference, Houston, TX, No. OTC 3065 
10. Wienke, J. and Oumeraci, H., (2005). Breaking Wave Impact Force on a Vertical and Inclined Slender Pile - Theoretical and Large-Scale Model Investigations. Coastal Engineering, 52, 435-462

11. Det Norske Veritas (DNV), (2010). RP-C205 Environmental Conditions and Environmental Loads. 